\title{
Sensory Feedback Induced by Front-Leg Stepping Entrains the Activity of Central Pattern Generators in Caudal Segments of the Stick Insect Walking System
}

\author{
Anke Borgmann, ${ }^{1}$ Scott L. Hooper, ${ }^{1,2}$ and Ansgar Büschges ${ }^{1}$ \\ ${ }^{1}$ Tierphysiologie, Zoologisches Institut, Universität zu Köln, 50931 Köln, Germany, and ²Department of Biological Sciences, Ohio University, Athens, Ohio \\ 45701
}

\begin{abstract}
Legged locomotion results from a combination of central pattern generating network (CPG) activity and intralimb and interlimb sensory feedback. Data on the neural basis of interlimb coordination are very limited. We investigated here the influence of stepping in one leg on the activities of neighboring-leg thorax-coxa (TC) joint CPGs in the stick insect (Carausius morosus). We used a new approach combining single-leg stepping with pharmacological activation of segmental CPGs, sensory stimulation, and additional stepping legs. Stepping of a single front leg could activate the ipsilateral mesothoracic TC CPG. Activation of the metathoracic TC CPG required that both ipsilateral front and middle legs were present and that one of these legs was stepping. Unlike the situation in real walking, ipsilateral mesothoracic and metathoracic TC CPGs activated by front-leg stepping fired in phase with the front-leg stepping. Local (intralimb) sensory feedback from load sensors could override this intersegmental influence of front-leg stepping, shifting retractor motoneuron activity relative to the front-leg step cycle and thereby uncoupling them from front-leg stepping. These data suggest that front-leg stepping in isolation would result in in-phase activity of all ipsilateral legs, and functional stepping gaits (in which the three ipsilateral legs do not step in synchrony) emerge because of local load sensory feedback overriding this in-phase influence.
\end{abstract}

\section{Introduction}

The fundamental rhythmicity of rhythmic motor patterns such as undulatory crawling and swimming, swimmeret beating, and legged locomotion arises from the activity of rhythmic central neural networks [(central pattern generators (CPGs)] [lamprey (Wallén and Williams, 1984); leech (Pearce and Friesen, 1984); crayfish swimmerets (Skinner and Mulloney, 1998); Manduca crawling (Johnston and Levine, 1996b); mammals (Kiehn and Kjaerulff, 1998); turtle (Stein, 2008); stick insect (Büschges, 2005)]. However, production of these patterns requires not only rhythmicity but also coordination of the body segments or appendages that produce the movements, and the neural basis of this coordination shows great interspecies and interbehavior variation.

In the case of undulatory crawling and swimming, although intersegmental proprioceptive feedback plays a role in this coordination, particularly when the movements are perturbed by environmental influences [eel (Wallén, 1982); lamprey (Grillner and Wallén, 2002); leech (Cang and Friesen, 2000)] (for review,

Received July 8, 2008; revised Jan. 29, 2009; accepted Jan. 31, 2009.

This work was supported by Deutsche Forschungsgemeinschaft (DFG) Grants Bu 857/6 and /8 and Schm 1084/ 2-2 (A.Bü.). S.L.H. was supported by National Institute of Mental Health Grant 57832 and DFG-Mercator Professorship K0142/111-1. We thank U. Bässler, M. Gruhn, and J. Schmidt for helpful discussions in the course of the work and R. A. DiCaprio for his comments on this manuscript. We thank H.-P. Bollhagen and S. Meyen-Southard for excellent technical assistance.

Correspondence should be addressed to Anke Borgmann, Zoological Institute, University of Cologne, Weyertal 119, 50923 Cologne, Germany. E-mail: anke.borgmann@uni-koeln.de.

D01:10.1523/JNEUROSCI.3155-08.2009

Copyright $\odot 2009$ Society for Neuroscience $\quad$ 0270-6474/09/292972-12\$15.00/0 see Liao, 2007), electrophysiology and modeling studies have shown that central coupling among the segmental CPGs is primarily responsible for intersegmental coordination [leech (Cang and Friesen, 2002); lamprey (Grillner, 2003); tadpole (Tunstall and Roberts, 1990, 1994); newt (Delvolvé et al., 1997)] (for review, see Hill et al., 2003), and thus central coupling appears to be of primary importance in intersegmental coordination.

In legged animals, alternatively, both intraleg [stick insect (Büschges, 2005); mudpuppy (Cheng et al., 1998); cat (Lam and Pearson, 2002; Pearson, 2008)] and interleg [stick insect (Cruse, 1990; Büschges et al., 1995; Cruse et al., 1995; Dürr et al., 2004; Ludwar et al., 2005); Manduca (Johnston and Levine, 1996a); cat (Akay et al., 2006); crayfish (Cruse and Müller, 1986; Cattaert and Le Ray, 2001); turtle (Samara and Currie, 2007); human (Haridas and Zehr, 2003)] coordination critically depend on proprioceptive feedback. The neural basis of joint coordination within single legs (intraleg coordination) has been extensively studied (see above references). The neural basis of interleg coordination is less understood.

We studied this issue by investigating the effect of movementinduced sensory input on segmental CPG activity in semiintact stick insect (Carausius morosus) preparations. When the middle legs or hind legs were removed, sensory signals from stepping front legs could entrain active ipsilateral mesothorax or metathorax-coxa (TC) joint (approximately analogous to human hip joint) CPGs. This entrainment resulted in in-phase activity of all active ipsilateral CPGs, an activity pattern that does not correspond to any known gait. Local load signals from the middle leg or hind leg could override the in-phase activity and shift middle 


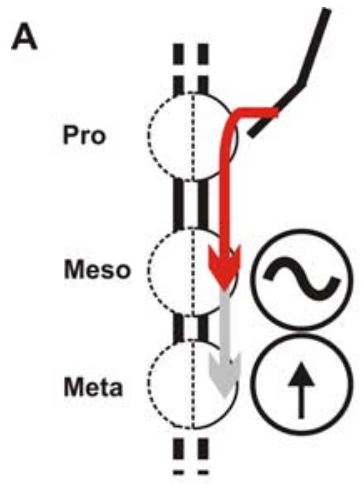

(Ludwar et al. 2005,

Borgmann et al. 2007)
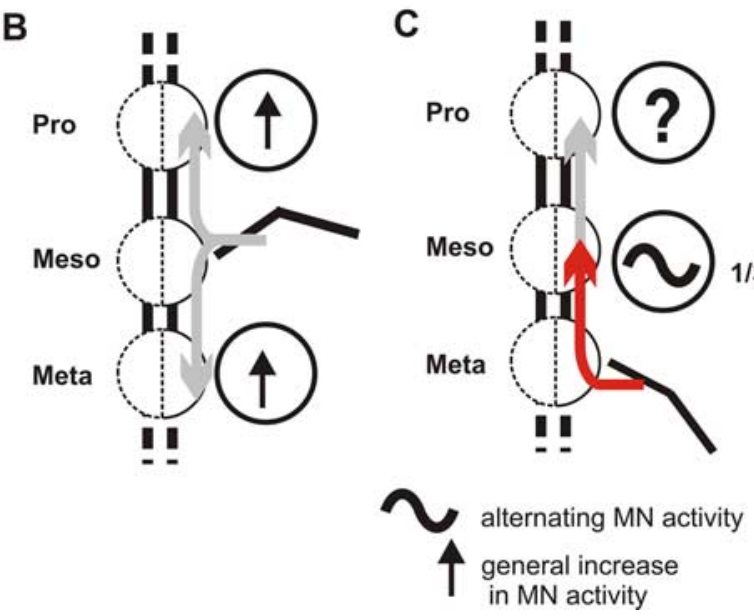

Figure 1. Summary of past work and a guide to the experiments presented here. $\boldsymbol{A}$, Stepping in single front legs induces alternating activity in mesothoracic protractor and retractor motor neurons and a generalized increase, but not rhythmicity, in metathoracic protractor and retractor motor neurons. $\boldsymbol{B}$, Stepping in single middle legs induces a generalized increase in activity, but not rhythmicity, in prothoracic and metathoracic protractor and retractor motor neurons. $\boldsymbol{C}$, In two-thirds of the preparations, backward stepping in single hind legs induces a generalized increase in activity, and in one-third of the preparations, rhythmicity in mesothoracic protractor and retractor motor neurons. The influence of hind leg backward stepping on prothoracic protractor and retractor MN activity has not been investigated (indicated by question mark in drawing).

leg and hind leg TC joint retractor motoneuron activity relative to the front-leg step cycle. These data demonstrate that front-leg sensory input plays a primary role in interleg coordination and suggest that interaction between intraleg and interleg sensory feedback is a primary mechanism underlying interleg coordination.

\section{Materials and Methods}

Experiments were conducted at room temperature $\left(18-24^{\circ} \mathrm{C}\right)$, generally under reduced light conditions, on adult, female Indian stick insects (Carausius morosus) (Brunner, 1907) from a colony maintained at the University of Cologne. All legs except a single front leg, or a single front leg and single ipsilateral middle leg or hind leg ("two-leg" preparations), were amputated at midcoxa. The animal was then fixed dorsal side up on a foam platform with dental cement (Protemp II; ESPE). The dorsal surface of the thorax was opened, the gut was moved aside, and connective tissue was carefully removed to expose the mesothoracic and metathoracic ganglia and their leg nerves for extracellular recording. The ganglion being recorded from was completely deafferented by cutting or crushing the lateral nerves ipsilateral and contralateral to the recording site and the body cavity was filled with saline (Weidler and Diecke, 1969). Extracellular recordings with monopolar hook electrodes [modified after Schmitz et al. (1991)] were made from leg nerves nl2, which contains protractor coxae motoneurons (MNs), and nl5, which contains retractor coxae MNs (Marquardt, 1940; Graham, 1985). In some analyses extracellular recordings were rectified and smoothed. The smoothing was performed with the SPIKE2 smoothing function. This process has one argument, a time period in seconds, $p$. The output at time $t$ is the average value of the input data points from time $t-p$ to $t+p$ seconds.

We wanted to activate (Chrachri and Clarac, 1987; Büschges et al., 1995 ) individual mesothoracic or metathoracic ganglia by applying the muscarinic ACh agonist pilocarpine $\left(5 \times 10^{-4} \mathrm{M}\right.$; Sigma-Aldrich $)$ to them alone while leaving the other ganglia in control saline. We first attempted to separate the ganglion of interest from the other ganglia by building silicon grease (highly viscous; Bayer) dams bounded by the inside surfaces of the lateral and ventral cuticle remaining between the ganglia. However, these dams always leaked because a good seal between the cuticle and silicon grease could not be achieved. We therefore removed a small, $\mathrm{U}$-shaped portion $(10-15 \mathrm{~mm}$ distant from the ganglion of interest) of the ventral and lateral cuticle between the ganglia, leaving the ganglia connected by only the connectives, and surrounded the connective and filled the gap between the separated regions of cuticle with silicon grease. This resulted in leak-free barriers [as verified by adding Janus Green B (Eastman Kodak) to the saline in the wells]. For mesothoracic ganglia, two silicon grease barriers were made (one between the mesothoracic and prothoracic ganglia and one between the mesothoracic and metathoracic ganglia). For the metathoracic ganglion, only one barrier (between the metathoracic and the mesothoracic ganglia) was required.

Animals walked on passive, lightweight, lowfriction treadmills (Bässler, 1993; Gabriel et al., 2003). In the two-leg preparation, each leg performed steps on its own treadmill and the legs were thus mechanically uncoupled. A DC motor attached to the treadmill measured treadmill velocity. The animal accelerated the treadmill during the stance phase, and nonzero treadmill velocity therefore indicates step stance phase. The start of the velocity increase was defined as stance beginning. The last maximum in the velocity trace before velocity began its decrease to zero was defined as stance end. In some experiments, stepping was further monitored by recording flexor EMG activity in the stepping leg with two thin $(40 \mu \mathrm{m})$ copper wires inserted into the proximal femur. Stepping sequences were elicited by gently touching the abdomen with a paintbrush. The paintbrush was removed as soon as the animal began stepping.

Data were recorded using a MICRO 1401 A/D converter and SPIKE2 data acquisition/analysis software (versions 3.13-4.12; Cambridge Electronic Design). Data evaluation and figure preparation were performed with custom-written scripts in the SPIKE2 software and in MATLAB 7.0 (Mathworks). Data were first analyzed using circular statistics (Rayleigh's test with a $\alpha$ value of 0.05 ) (Batschelet, 1981) with respect to phase in the walking leg step cycle, defined by stance beginning. Phase histograms were used to compare motor neuron activity in steps with different cycle periods. The influence of a stepping leg on pilocarpine-induced motor rhythms was analyzed by phase response curves. In the text and figures, $N$ is animal number, and $n$ is sample size.

\section{Results}

Previous work on the neural basis of intersegmental coordination in the walking stick insect has been done mainly in single-leg preparations and is summarized in Figure 1. Stepping in single front legs induces rhythmic activity in mesothoracic protractor and retractor motor neurons and a generalized increase, but not rhythmicity, in metathoracic activity (Fig. 1A) (Ludwar et al., 2005; Borgmann et al., 2007). From these data, we could not distinguish between two possibilities: either front-leg-induced sensory input driving motor neurons directly, or this sensory input instead activating the mesothoracic CPG. Stepping in single middle legs induces a generalized increase in activity, but not rhythmicity, in metathoracic protractor and retractor motor neurons (Fig. 1B) (Borgmann et al., 2007). Forward stepping in single hind legs induced a generalized increase in activity, but not rhythmicity, in prothoracic and mesothoracic protractor and retractor motor neurons (Fig. 1C) (new data) (this study). Backward stepping in single hind legs induced a generalized increase in mesothoracic protractor and retractor motor neuron activity in two-thirds of the preparations and rhythmic activity in onethird $(N=9)$ (Fig. 1C) (Borgmann et al., 2007). The effect of hind leg backward stepping on prothoracic motor neuron activity is unknown. Furthermore, in none of this previous work has the effect of having two legs present been examined. We describe here the effect on mesothoracic and metathoracic walking CPG activ- 
ity of walking in single front legs, of simultaneous walking in front and middle legs, and of simultaneous walking in front leg and hind leg.

\section{Influence of stepping of a single front leg on pilocarpine-activated middle-leg TC joint CPGs}

We first investigated the effect of single front-leg stepping on mesothoracic TC joint CPG activity (this CPG coordinates retractor and protractor $\mathrm{MN}$ activity, which moves the entire leg back and front similar to movement at the human hip). The mesothoracic CPG was activated by applying pilocarpine $(N=6)$ to only the mesothoracic ganglion (Fig. 2) (Büschges et al., 1995). Figure $2 A$ shows a schematic of the experimental set-up (left panel) and extracellular recordings of mesothoracic protractor and retractor MNs during front-leg stepping sequences (right panel). In the first stepping sequence (left portion of right panel), the mesothoracic ganglion was not superfused by pilocarpine. Mesothoracic protractor and retractor $\mathrm{MN}$ activity alternated and was in phase with front-leg stepping (Borgmann et al., 2007). Application of pilocarpine to the mesothoracic ganglion in the absence of front-leg stepping induced a very slow (on average, $0.2 \mathrm{~Hz}$ ) rhythmic alternation of mesothoracic protractor and retractor MN activity (middle portion of right panel) (Büschges et al., 1995). When the front leg began stepping (red vertical line), the burst duration and cycle period of the pilocarpine-induced mesothoracic protractor and retractor MN rhythm decreased and the mesothoracic activity became entrained to the front-leg stepping.

A phase analysis was performed to quantify the changes front-leg stepping induced in the pilocarpine-activated mesothoracic activity. The histogram in Figure $2 \mathrm{~B}$ shows the distribution of mesothoracic protractor and retractor $\mathrm{MN}$ spikes in the front-leg step cycle for 154 steps for the preparation shown in $A$ (data from other preparations were similar). Retractor $\mathrm{MN}$ activity (black bars) increased at stance beginning, had a maximum between phases of 60 and $90^{\circ}$, and then decreased. Protractor MN activity (gray bars) began to increase at $180^{\circ}$ and had a maximum between 270 and $300^{\circ}$. The mean end of front-leg stance was $147^{\circ}$ (black square at top of histogram). Assuming that pilocarpine activates the same CPGs that are usually activated during walking, these experiments show that front-leg stepping entrained the output of active mesothoracic TC joint CPGs. Mesothoracic protractor activity was active with front-leg swing (protractor) motor neurons and mesothoracic retractor activity with front-leg stance (retractor) motor neurons, consistent with the phase relationships observed when front-leg stepping alone (no mesothoracic pilocarpine application) activated rhythmic activity in silent mesothoracic ganglia (Fig. $2 \mathrm{~A}$, left portion of right panel) (Borgmann et al., 2007). slope near 1.
Application of $5 \times 10^{-4} \mathrm{M}$ pilocarpine on only the mesothoracic ganglion
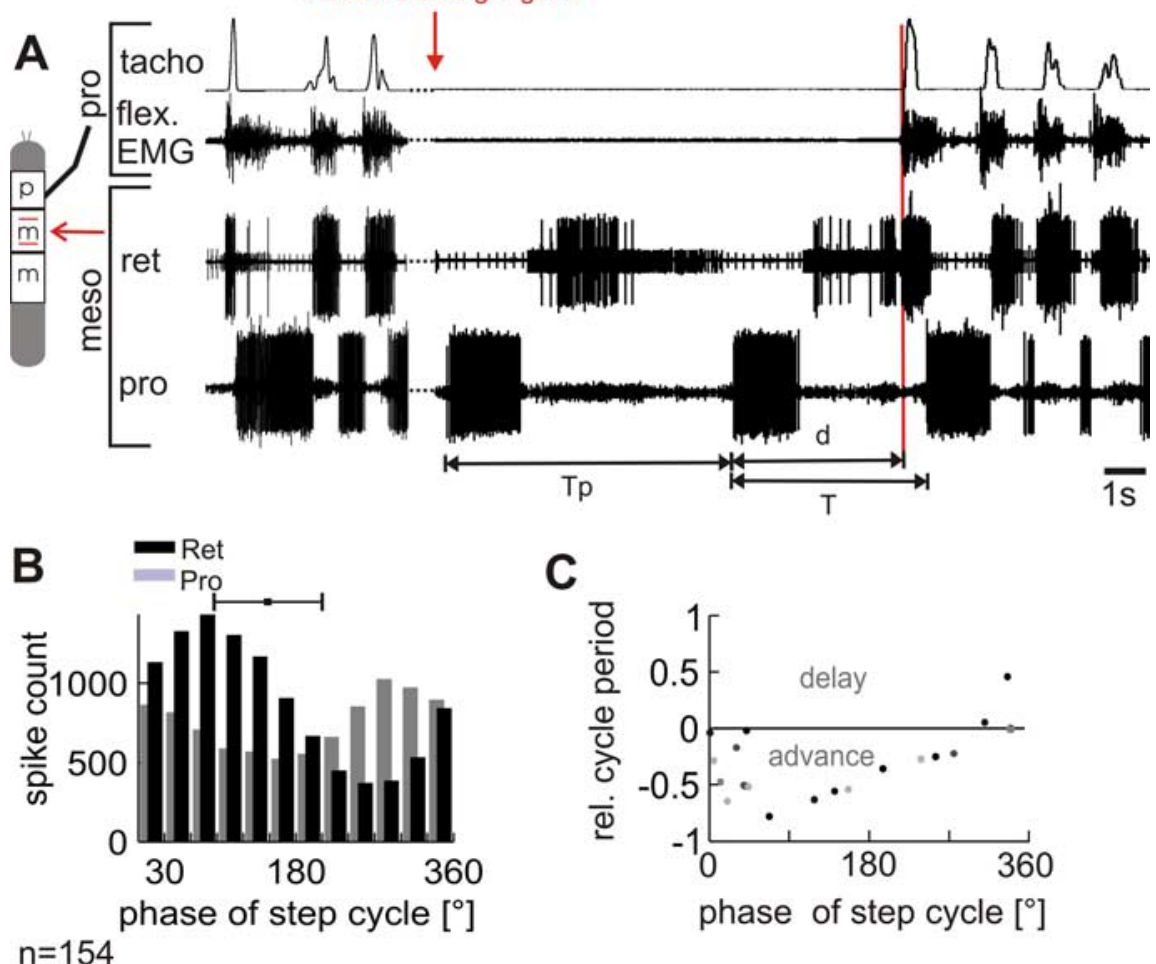

Figure 2. Front-leg stepping entrained pilocarpine-activated mesothoracic TC joint CPGs. $\boldsymbol{A}$, Left, Schematic of experimental front-leg stepping. Protractor and retractor MN activity alternated and was in phase with front-leg stepping. $\boldsymbol{A}$, Middle portion of front-leg stance; error bars are angular SD. Protractor activity was maximum between 270 and $300^{\circ}$, and retractor MN was and $90^{\circ}$, of front-leg cycle period. C, Phase response curve. Relative change in pilocarpine-induced mesothoracic protractor burst cycle $(d / T)$ for six experiments (gray to black dots). In the first $70^{\circ}$ of the cycle, a step advanced the next mesothoracic protractor burst from zero to $60 \%$ (see Results). Between 70 and $300^{\circ}$, the phase response curve was linear with a

A phase response curve was used to characterize the influence of front-leg stepping on mesothoracic TC joint CPG activity. To calculate the phase response curve, the cycle period of the mesothoracic pilocarpine rhythm was averaged over at least four cycles directly preceding the first step of the front-leg stepping sequence. A cycle was defined from the beginning of one protractor burst to the beginning of the next (Fig. $2 \mathrm{~A}$, middle portion of right panel). The relative change in mesothoracic cycle period induced by the first step of the front-leg stepping sequence was plotted against the phase in the mesothoracic rhythm at which this step occurred (Fig. 2C) $(N=6)$. A negative change in cycle period corresponds to a phase advance of the next protractor burst, a positive change to a phase delay. The phase response curve was negative or near negative at all phases, indicating that front-leg steps always advanced the next protractor burst. In the first $70^{\circ}$ of the mesothoracic cycle, a front-leg step advanced the next protractor burst from zero to $60 \%$. Seventy degrees corresponds to approximately two-thirds of the protractor burst, and close examination of the data showed that a front-leg step occurring during these phases did not always end the ongoing protrac- 

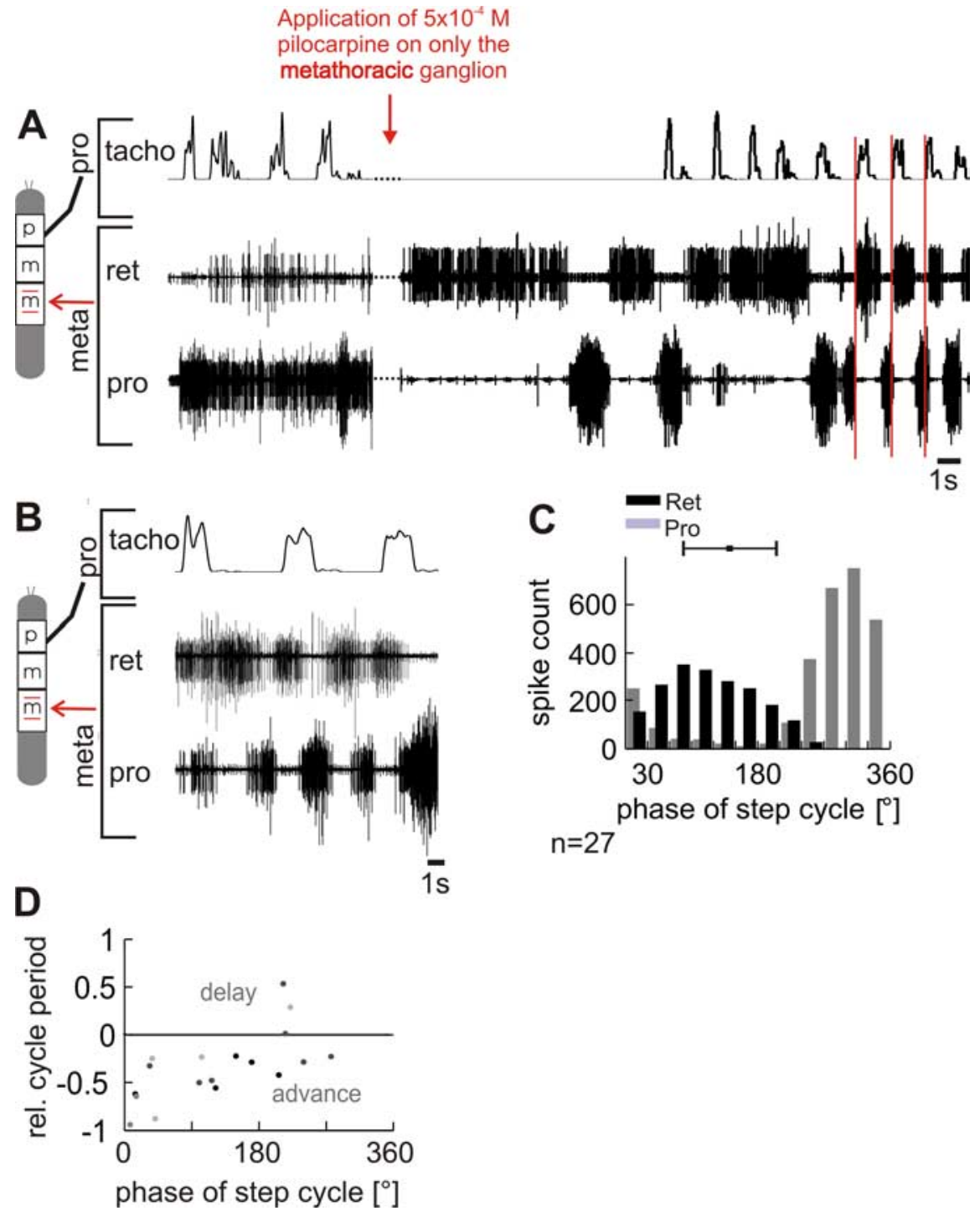

Figure 3. Front-leg stepping entrained pilocarpine-activated metathoracic TC joint CPG. $A$, Left, Schematic of experimental setup. $\boldsymbol{A}$, Left portion of right panel, Extracellular recordings of metathoracic protractor and retractor MNs during front-leg stepping sequences in control conditions. Front-leg stepping was accompanied by a generalized increase in motoneural activity but no bursting activity. $A$, Middle portion of right panel, Pilocarpine application $\left(5 \times 10^{-4} \mathrm{M}\right)$ to the metathoracic ganglion induced a very slow rhythmic alternation in metathoracic protractor and retractor motor neurons. Front-leg stepping entrained the pilocarpine-induced metathoracic protractor and retractor $\mathrm{MN}$ rhythmic activity after a few steps (right portion of right panel) $(N=4) . B$, A preparation in which front-leg stepping decreased pilocarpine-activated metathoracic protractor and retractor MN burst duration and cycle period, but metathoracic activity was not entrained to front-leg stepping $(N=1)$. C, Phase histogram of the experiment shown in $\mathbf{A}$ : Distribution of protractor (gray) and retractor (black) MN activity in front-leg step cycle for 27 steps after entrainment of pilocarpine-induced metathoracic rhythmicity to front-leg stepping had been established. Protractor MN maximum activity occurred between 300 and $330^{\circ}$, and retractor MN maximum activity between 60 and $90^{\circ}$. D, Phase response curve: relative change in pilocarpine-induced metathoracic protractor cycle period plotted versus phase of the first step of a front-leg stepping sequence in the metathoracic protractor cycle for all four experiments (gray to black dots). A front-leg step occurring in the first $45^{\circ}$ of the metathoracic protractor cycle period shortened metathoracic protractor cycle period on average $65 \%$; a step occurring between 45 and $180^{\circ}$ shortened metathoracic protractor cycle period on average $37 \%$. pro, Protractor; ret, retractor; tacho, tachometer trace.

tor burst. It is thus possible that for stepping sequences beginning in this phase window, a second step was required before entrainment was achieved. Between 70 and $300^{\circ}$, the phase response curve was linear with a slope of $\sim 1$, which indicates that front-leg stepping occurring during these phases terminated the protractor bursts. The influence of front-leg steps on pilocarpine-induced mesothoracic protractor and retractor MN activity thus appeared to be stronger at the end of protractor bursts and during retractor bursts.
Influence of stepping of a single front leg on pilocarpine-activated hind leg TC joint CPGs

The influence of stepping of a single front leg on quiescent (no pilocarpine application) metathoracic protractor and retractor MNs qualitatively differed from its effects on mesothoracic MNs. Single frontleg stepping increased metathoracic MN firing but did not induce alternating $\mathrm{MN}$ bursting (Fig. 3A, left portion of right panel) (Borgmann et al., 2007). These data indicated that sensory signals induced by front-leg stepping did not activate the metathoracic TC joint CPG, but did not prove that such signals would not affect an already-activated metathoracic CPG. We therefore measured the effect of front-leg stepping on metathoracic protractor and retractor $\mathrm{MN}$ activity $(N=5)$ in metathoracic TC joint CPGs activated by applying pilocarpine to the metathoracic ganglion alone. Figure $3 A$, right panel, shows extracellular recordings of pilocarpineactivated metathoracic protractor and retractor MN activity before (middle portion of panel) and during (right portion of panel) front-leg stepping. Pilocarpine application alone induced alternating activity in metathoracic protractor and retractor MNs with cycle frequencies (in this experiment, on average, $0.13 \mathrm{~Hz}$ ) in the same range as described above for mesothoracic protractor and retractor $\mathrm{MN}$ activity under pilocarpine. In five of five preparations, the burst duration and cycle period of pilocarpine-activated metathoracic protractor and retractor MN activity decreased when front-leg stepping began. In four of these preparations, metathoracic protractor and retractor $\mathrm{MN}$ activity became entrained by front-leg stepping (Fig. $3 \mathrm{~A}$, right portion of right panel, vertical red lines). In one preparation, front-leg stepping markedly shortened pilocarpine-induced metathoracic protractor and retractor MN bursts but entrainment did not occur (Fig. 3B).

For the four preparations in which the pilocarpine-induced metathoracic activity became entrained to front-leg stepping, we analyzed the distribution of metathoracic protractor and retractor $\mathrm{MN}$ activity in the front-leg step cycle (Fig. $3 C$ ) (the data shown are for the preparation in Fig. 3A, but the data from all four preparations were similar). It always took three to five front-leg steps for the metathoracic rhythm to become entrained, and we performed this analysis only for steps ( $n=27$ in this preparation) after which this had occurred; the analysis is otherwise identical with that performed to produce Figure $2 B$. Protractor MN activity was maximum between 300 and $330^{\circ}$ of front-leg step cycle and retractor $\mathrm{MN}$ activity between 60 and $90^{\circ}$. As with the mesothoracic 
TC joint CPG, retractor MNs were thus mainly active during stance and protractor MNs during the swing phase.

We also performed a phase response analysis (exactly as in Fig. 2C) of the effect of the first front-leg step on metathoracic protractor cycle period for all five preparations (Fig. 3D, gray to black dots). When first front-leg steps occurred between 0 and $180^{\circ}$ of the protractor cycle, the phase response was always negative, indicating that the next protractor burst had been advanced and thus protractor cycle period shortened. When the front-leg step occurred in the first $45^{\circ}$ of the metathoracic cycle, mean metathoracic cycle period shortened $65 \%$. When the front-leg step occurred between 45 and $180^{\circ}$ of the metathoracic cycle, mean metathoracic cycle period shortened by $37 \%$. Steps occurring in the second one-half of the metathoracic cycle had no clear effect on metathoracic cycle period.

\section{Entrained mesothoracic and} metathoracic TC joint CPGs are active in phase

The distributions of protractor and retractor MN activity in the front-leg step cycle seen in Figures $2 B$ and $3 C$ suggest that, when entrained by front-leg stepping, the mesothoracic TC joint CPG and pilocarpine-activated metathoracic TC joint CPG would be active in phase. To confirm this, we recorded mesothoracic and pilocarpine-activated metathoracic activity simultaneously during front-leg stepping (Fig. $4 A$ ). The bottom trace in this panel shows rectified, smoothed ( $p=$ $0.05 \mathrm{~s}$ ) (see Materials and Methods), and overlaid extracellular recordings of metathoracic (red) and mesothoracic (black) retractor activity. The activities of the two ganglia are largely in phase, although there is a tendency for metathoracic activity to occur somewhat before mesothoracic activity. This tendency was characterized by averaging the rectified and smoothed mesothoracic and metathoracic retractor MN waveforms (Fig. 4B) using front-leg stance beginning as the reference time point (dashed vertical line). Metathoracic retractor MN activity began on average $0.3 \mathrm{~s}$ before front-leg stance beginning, some $0.15 \mathrm{~s}$ earlier than mesothoracic retractor activity. Metathoracic retractor MN activity was maximal from $\sim 0.1 \mathrm{~s}$ before to $0.1 \mathrm{~s}$ after front-leg stance beginning, whereas mesothoracic retractor MN activity was maximum $0.2 \mathrm{~s}$ after front-leg stance beginning.

This average waveform analysis was performed on an additional 11 experiments (Fig. 4C), two with simultaneous recordings of mesothoracic and metathoracic retractor activity (including the one shown in Fig. $4 B$ ), three with recordings of only metathoracic retractor MNs, and seven with recordings of only mesothoracic retractor MNs (two of which were pilocarpineactivated). The amplitudes of the waveforms were normalized to

B
Application of $5 \times 10^{-4} \mathrm{M}$

pilocarpine on only the metathoracic ganglion
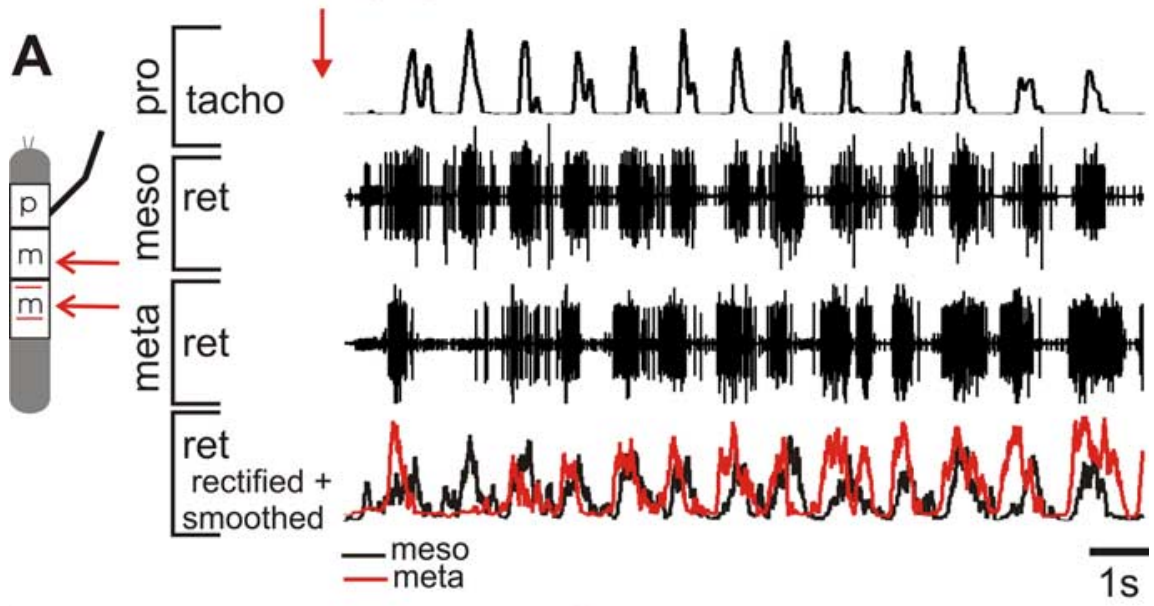

C

Active in phase. $A$, Extracellular recordings of mesothoracic and pilocarpine-activated metathoracic retractor $\mathrm{MN}$ activity during front-leg stepping $(N=5)$. Bottom trace, Rectified, smoothed ( $p=0.05$ s) (see Materials and Methods), and overlaid extracellular recordings of metathoretrator MN waveforms. Front-leg stance beginning (dashed vertical line) is reference time point. Metathoracic retractor activity began on average $0.3 \mathrm{~s}$ before and was maximum from $\sim 0.1 \mathrm{~s}$ before to $0.1 \mathrm{~s}$ after front-leg stance beginning. Metathoracic retractor $\mathrm{MN}$ activity began on average $0.15 \mathrm{~s}$ before and was maximum $0.2 \mathrm{~s}$ after front-leg stance beginning. $C$, Normalized averaged rectified and smoothed mesothoracic (black; $N=9$ ) and metathoracic (red; $N=5$ ) retractor MN recordings using activity; 3 recordings of only metathoracic retractor MNs; 7 recordings of only mesothoracic retractor MNs, 2 of which were pilocarpine-activated). The activity of metathoracic MNs tended to increase and reach maximal intensity before that of mesothoracic MNs. ret, Retractor; tacho, tachometer trace.

1. Because we were interested in the time relationship between mesothoracic and metathoracic retractor MN bursts relative to the beginning of front-leg stance, we used overlays plotted in the time domain. Performing the analyses in the time domain rather than the phase domain was valid because the front-leg step-cycle frequencies of the mesothoracic and metathoracic experiments were similar. These data are consistent with those shown in Figure $4 B$, with metathoracic activity $(N=5)$ both beginning and reaching its maximum before mesothoracic activity $(N=7)$ did. It is important to stress, however, that these differences were not large enough to negate the fundamental point of the figure, that metathoracic and mesothoracic retractor activity both occurred during front-leg stance. Under these conditions, unlike the situation during walking in the intact animal, in which the middle leg cycles out of phase with 


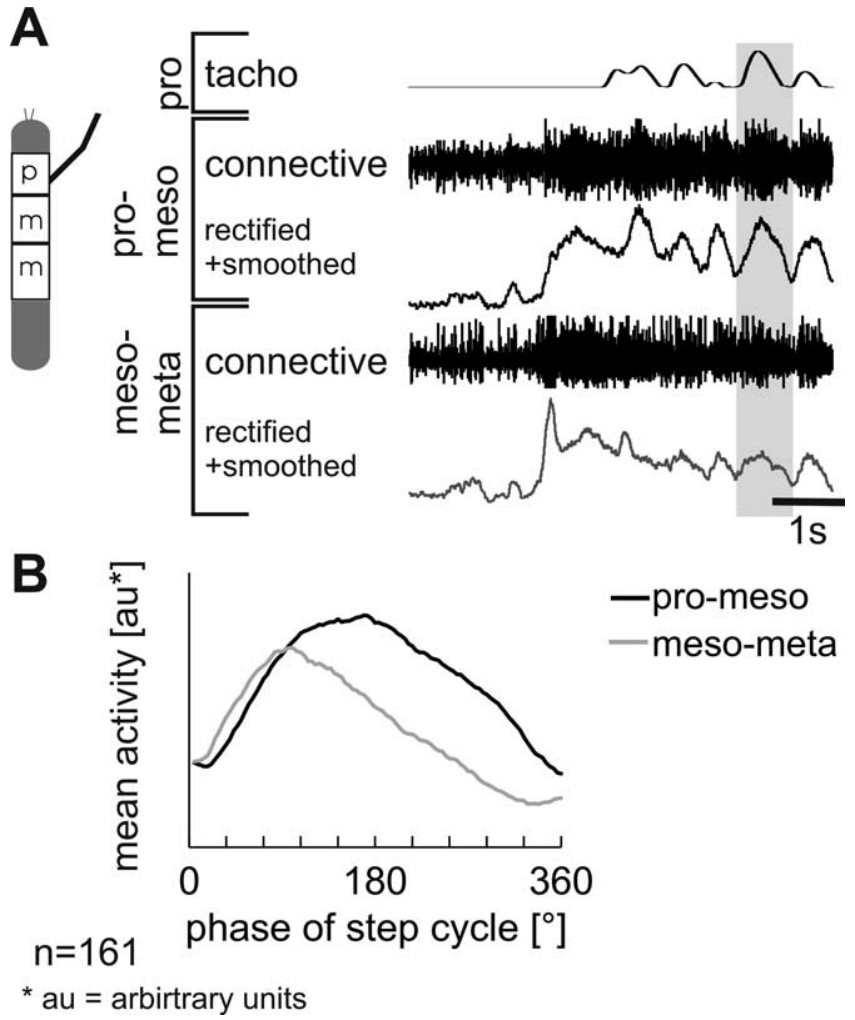

Figure 5. Front-leg stepping increased ipsilateral connective neuronal activity. $\boldsymbol{A}$, Extracellular recordings of the pro-meso and meso-meta connectives during a front-leg stepping sequence. The third and fifth trace are rectified and smoothed ( $p=0.05 \mathrm{~s}$ ) transforms of the corresponding extracellular recordings from the pro-meso (second trace) and meso-meta (fourth trace) connectives, respectively. Neural activity in both connectives was modulated with front-leg stepping. The gray box marks one front-leg step cycle. tacho, Tachometer trace. $\boldsymbol{B}$, Waveform averages of the rectified and smoothed recordings relative to front-leg step cycle $\left(0^{\circ}\right.$ corresponds to stance beginning). Activity in the pro-meso connective (black) and meso-meta connective (gray) increased at the beginning of front-leg stance. Neural activity in the promeso connective was maximum at $169^{\circ}$ and in the meso-meta connective at $97^{\circ}$ of the frontleg step cycle.

the front leg and hind leg, the TC joint CPGs of all three ganglia thus cycled in approximate synchrony.

\section{Front-leg stepping modified pro-meso and meso-meta ipsilateral connective activity}

The data showing that inputs activated by front-leg stepping altered mesothoracic and metathoracic activity implies that frontleg stepping should produce corresponding changes in activity in the pro-meso and meso-meta ipsilateral connectives. Extracellular recordings from the connectives (Fig. $5 \mathrm{~A}$ ) confirmed this suggestion; the modulation was particularly apparent in rectified and smoothed traces ( $p=0.05 \mathrm{~s}$ ). Comparison of the pro-meso and meso-meta activity once good rhythmic activity in the metathoracic ganglion had been achieved (gray box) suggested that the absolute variation between maximum and minimum activity was greater in the pro-meso connective than the meso-meta connective. This difference in the size of the amplitude variation present in the two connectives was seen in four of five experiments, but quantitative comparison of these differences is problematic because of possible variation in extracellular electrode placement and recording quality. However, these data are sufficient to quantitatively compare when in the front-leg step cycle the increased activity occurred in the two connectives. These averages of the rectified and smoothed traces showed that neural activity in both connectives began to increase at front-leg stance beginning $\left(0^{\circ}\right)$, but meso-meta activity reached its maximum (at 97 $)$ and decreased earlier, than pro-meso activity (maximum at $169^{\circ}$ ) (Fig. $5 B$, meso-meta activity, gray; pro-meso activity, black). Despite these timing differences, the effects of front-leg stepping on activated mesothoracic and metathoracic TC joint CPG activity were comparable (Fig. 4).

\section{Influence of two-leg stepping on TC joint CPG activation and coordination}

In the experiments described thus far, only a single front leg was present. We also investigated the influence of two stepping legs on the activation of segmental CPGs. In the two-leg experiments, the front leg and contralateral middle leg, the front leg and ipsilateral middle leg, or the front leg and ipsilateral hind leg were left intact, and the legs performed stepping movements on two separate passive treadmills.

When a front leg and the contralateral middle leg were present, metathoracic rhythmic bursting activity, on either side of the animal, was very rarely observed (zero of four metathoracic recordings ipsilateral to the front leg; one of five metathoracic recordings contralateral to the front leg). However, when the front and ipsilateral middle legs were present, stepping in either leg reliably (11 of 12 experiments) elicited alternating burst activity in ipsilateral metathoracic retractor and protractor MNs. Figure $6 \mathrm{~A}$ shows alternating metathoracic retractor and protractor $\mathrm{MN}$ bursts during front-leg steps (first trace) with the middle leg standing (middle trace) (left portion of right panel) and with both the front and middle legs stepping (right portion of right panel). Figure $6 B$ shows alternating metathoracic retractor and protractor MN bursts during middle-leg stepping (second trace) with the front leg standing (first trace).

In 5 of the 11 experiments with front and ipsilateral middle legs in which metathoracic alternating activity was present, the metathoracic bursts were strongly phase coupled to front-leg stepping, continuously in three experiments and during several stepping sequences in the other two. To quantify this phase coupling, we performed a detailed analysis of metathoracic motor neuron activity as a function of front-leg step cycle. Figure 6, A and $C$, shows this analysis for one experiment. In part of the walking sequence shown in Figure $6 A$ (right portion of right panel), the front and middle legs walked simultaneously but the two legs stepped independently, with the front leg stepping more slowly than the middle leg. In this case, the alternating bursts of metathoracic protractor and retractor MNs activity were phase locked to the front-leg steps (red vertical lines). In this experiment, the mean end of front-leg stance in the front-leg step cycle was $102^{\circ}$ (Fig. 6C, black square at top). Metathoracic retractor MNs (black bars) were active during front-leg stance and the beginning of swing (maximum activity between 60 and $90^{\circ}$ of the front-leg step cycle) and protractor MNs (gray bars) were active during front-leg swing (maximum activity between 180 and $210^{\circ}$ ). These phase relationships were similar to those observed between single front-leg stepping and metathoracic protractor and retractor $\mathrm{MN}$ activity when the metathoracic CPG was activated with pilocarpine (Fig. 3 C). Similar phase relationships were observed in all five experiments in which metathoracic activity was phase coupled to front-leg stepping.

In the other six experiments, the metathoracic protractor and retractor bursts were not entrained with either leg and typically occurred with different cycle periods than either anterior leg's stepping cycle (Fig. 6D). It was nonetheless possible that, although the front and middle leg activities were too weak to en- 


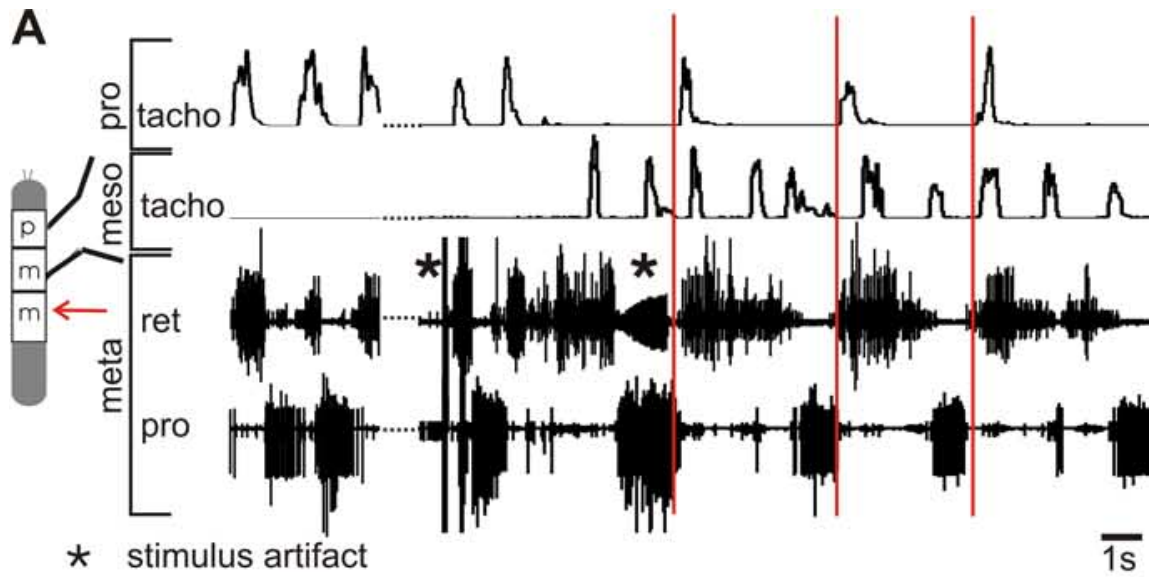

B
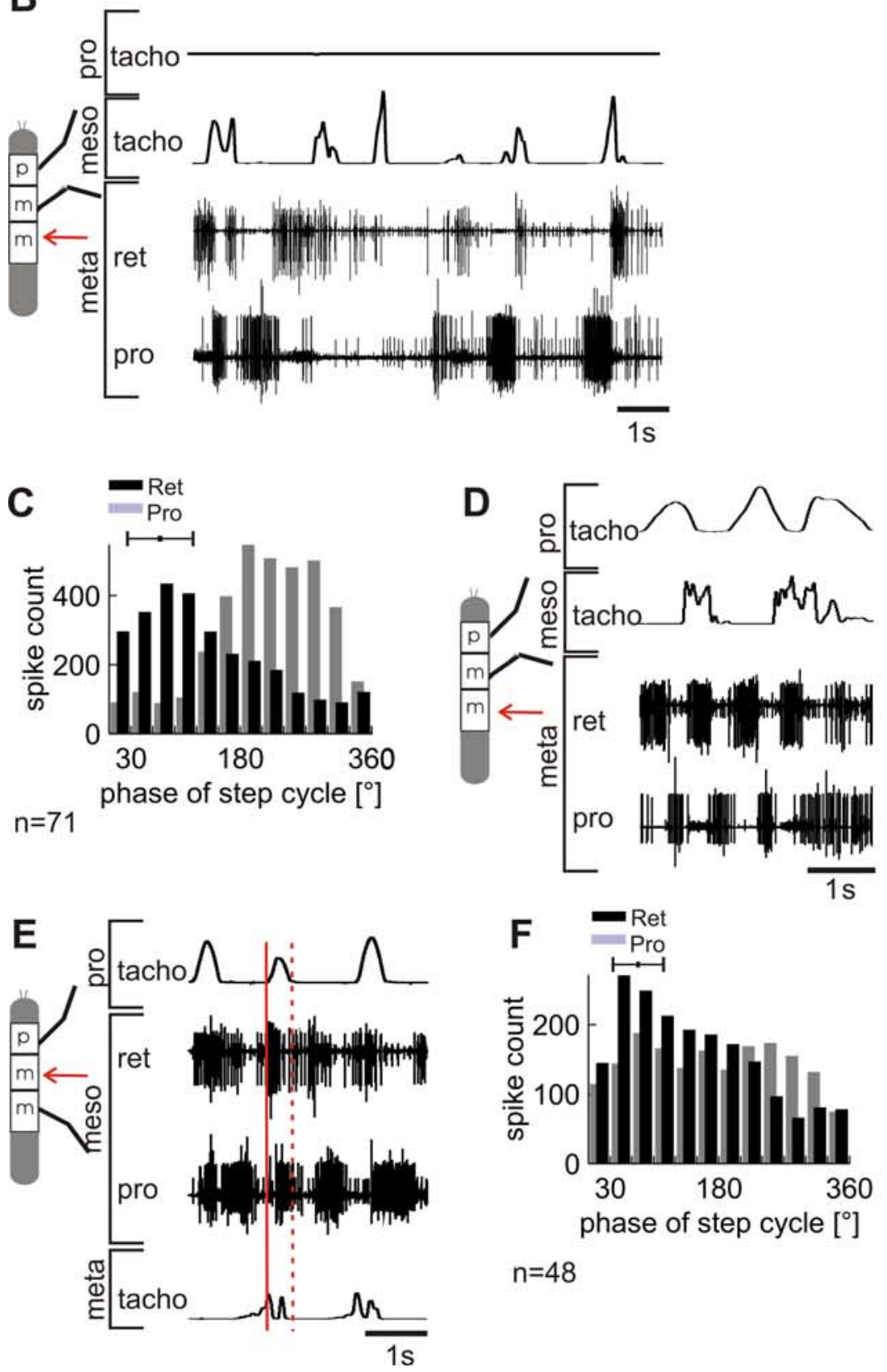

$n=48$

Figure 6. Stepping of two ipsilateral legs activated the CPG of the remaining ipsilateral hemiganglion. $A$, Extracellular recordings of metathoracic protractor and retractor MN activity during front-leg stepping while the middle leg was standing (left portion of right panel) and when both the front and ipsilateral middle legs stepped (right portion of right panel). Metathoracic protractor train the metathoracic activity, front or middle leg activity was still influencing metathoracic activity. Analyses similar to those performed in Figure $6 C$ were performed to test for such weak influences. These analyses showed that metathoracic retractor spike number varied significantly (see Materials and Methods) as a function of front-leg step phase in three, and metathoracic protractor spike number in zero, of these six experiments. Metathoracic retractor spike number varied significantly as a function of middle-leg phase in 2 , and metathoracic protractor activity in 6 , of the 11 experiments.

Qualitatively similar results were obtained for two-leg preparations in which the front leg and ipsilateral hind leg were intact. Alternating bursting activity occurred in the mesothoracic protractor and retractor $\mathrm{MNs}$ when either the ipsilateral front leg or hind leg stepped (Fig. 6E) $(N=8)$. In no experiments was mesothoracic bursting activity coupled to hind leg stepping. In three of eight experiments, mesothoracic burst activity was strongly phase-coupled to front-leg stepping, similar to that observed in the single front-leg experiments (Fig. $2 \mathrm{~B}$ ). In the other five experiments, this coupling was less apparent

\footnotetext{
and retractor MN bursts alternated and were phase locked to front-leg steps (red vertical lines) regardless of middle-leg stepping. ( $N=5 ; 3$ continuously, 2 episodically). $\boldsymbol{B}$, Extracellular recordings of metathoracic protractor and retractor $\mathrm{MN}$ activity during middle-leg stepping sequences while the front-leg was standing. Protractor and retractor MN bursts alternated. C, Distribution of metathoracic retractor (black bars) and protractor (gray bars) MN activity in the front-leg step cycle for 71 steps. Retractor MN activity was maximum between 60 and $90^{\circ}$. Protractor MN activity was maximum between at 180 and $210^{\circ}$. D, Metathoracic protractor and retractor MN activity during simultaneous ipsilateral front- and middle-leg stepping in which no entrainment occurred (6 of 11 preparations). Protractor and retractor MN cycle period was more rapid than either leg's step frequency. No phase coupling to front- or middle-leg steps was observed. E, Mesothoracic protractor and retractor $\mathrm{MN}$ activity during simultaneous ipsilateral front leg and hind leg stepping sequences. Phase coupling to hind leg stepping was never observed. Phase coupling of mesothoracic protractor and retractor MN activity to front-leg steps was less apparent. Switching between mesothoracic protractor and retractor MN activity occurred more than once in one front-leg step cycle (red vertical line and red dotted line). $\boldsymbol{F}$, Analysis of spiking activity in twoleg preparations such as those in $\boldsymbol{C}$ in front-leg step phase showed that mesothoracic protractor and retractor activity nonetheless significantly varied as a function of front-leg phase. Distribution of mesothoracic protractor and retractor MN spike activity in the front-leg step cycle for 48 steps from one preparation showed a significant variation as a function of front-leg phase $(N=7)$. Retractor MN activity was maximum between 30 and $60^{\circ}$. Protractor MN activity had no clear maximum. pro, Protractor; ret, retractor; tacho, tachometer trace.
} 


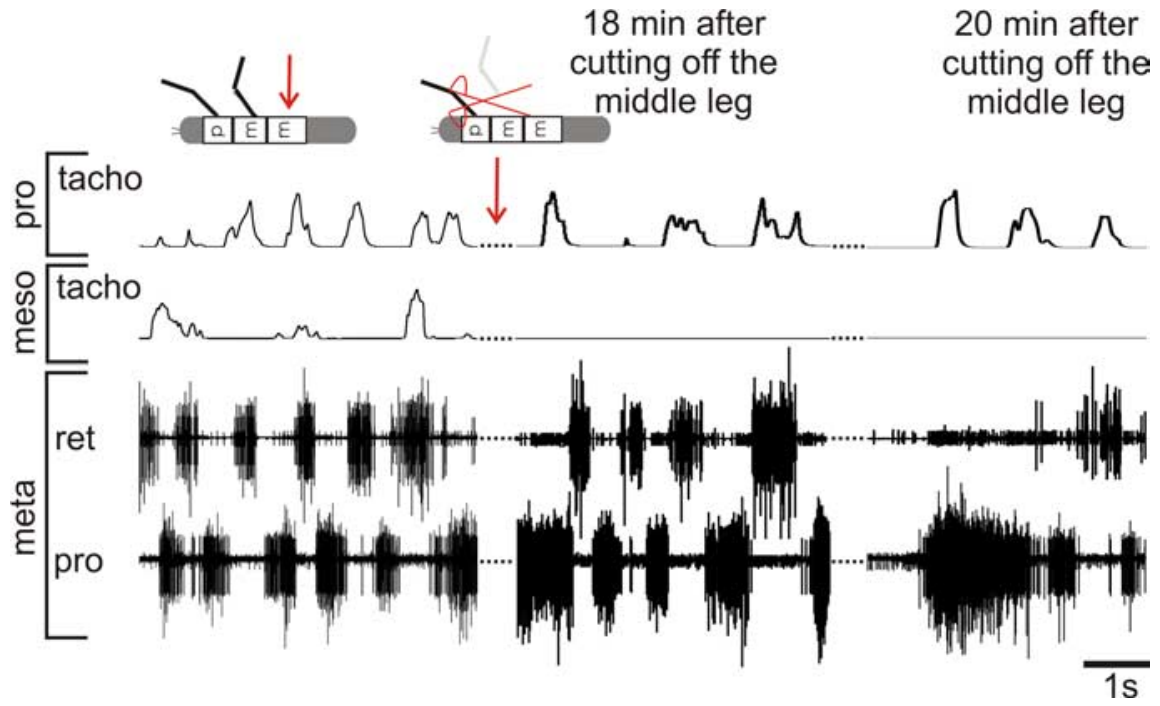

Figure 7. Middle-leg influences were long-lasting. Left, Extracellular recordings of metathoracic protractor and retractor MN activity during simultaneous front- and middle-leg stepping sequences. Metathoracic protractor and retractor MN activity alternated during front- and middle-leg stepping. Middle, Eighteen minutes after middle-leg removal. Protractor and retractor MN activity still alternated during front-leg stepping. Right, Twenty minutes after middle-leg removal, metathoracic activity became nonalternating. pro, Protractor; ret, retractor; tacho, tachometer trace.

(Fig. $6 E$ shows one of these experiments). However, analysis of spiking activity in front-leg step phase showed that in four of even these five experiments mesothoracic retractor and protractor activity nonetheless varied significantly as a function of front-leg phase (Fig. $6 F$ ). In most of these plots, however, the variation was less strongly peaked than in the single front-leg preparations, perhaps indicating that the presence of the hind leg lessened the effect of front-leg movement on mesothoracic activity (compare Figs. $2 B, 6 F)$.

In summary, in the presence of both the ipsilateral front and middle legs, stepping in either leg alone activated the metathoracic TC joint CPG. This contrasts with single front-leg or single middle-leg preparations, in which metathoracic rhythmic activity was never observed. In preparations with intact ipsilateral front and middle legs, front-leg stepping alone, but never middleleg stepping alone, could entrain the metathoracic TC joint CPG. In contrast, in two-leg preparations with a contralateral middle leg, neither front-leg nor middle-leg stepping induced rhythmic activity in either the ipsilateral or contralateral metathoracic hemiganglia. In preparations with intact ipsilateral front leg and hind leg, walking in either leg activated the mesothoracic TC joint CPG, but entrainment, when it occurred, was always to the front leg.

Middle-leg influences on front-leg effects only slowly decayed after middle-leg ablation

The data in Figure 6 show that the presence of two ipsilateral legs allowed stepping in either leg to activate rhythmic bursting in metathoracic protractor and retractor motor neurons, whereas the presence of a single stepping front leg caused a generalized, nonalternating increase in metathoracic protractor and retractor motor neuron activity. We were interested in whether this enhancement of the capacity for metathoracic rhythmicity by middle-leg presence was attributable to short-acting excitatory effects or longer-lasting, perhaps modulatory, influences. To test this possibility, we cut off the middle leg in two preparations in which metathoracic alternating activity was being expressed when both legs were present. After middle-leg removal, metathoracic alternating activity declined very slowly, continuing for tens of minutes after middle-leg removal (Fig. 7). In both cases, metathoracic activity eventually became nonalternating, as in the single front-leg experiments shown previously (Fig. 3A).

\section{Influence of local load signals on the} middle-leg TC joint CPG during front-leg stepping

In tripod walking, front- and middle-leg steps are out of phase (Collins and Stewart, 1993). In tetrapod walking, front- and middle-leg stance or swing can overlap, but the centers of the motor neuron activities are still clearly not coincident (Graham, 1985). However, in our single frontleg preparations, mesothoracic bursting activity was in phase with front-leg steps (retractor MNs active during front-leg stance, protractor MNs during front-leg swing). One explanation for this disparity is that, in intact animals, middle-legderived sensory inputs to the mesothoracic ganglion override the front-leg sensory-induced entrainment, and hence cause the legs to be active out of phase. To investigate this issue, we used a preparation with an intact single front leg and one-half to two-thirds of the middle-leg femur left intact. The middle-leg motor nerves were cut so that the leg could not move under the influence of mesothoracic motor neuron activity, but middle-leg sensory input could still reach the mesothoracic ganglia via the intact nervus cruris. We then mimicked the effect of activation of campaniform sensilla (CS) by middle-leg loading during walking by rhythmically bending the femur with a piezoelectric device while recording from mesothoracic protractor and retractor motor neurons (Schmitz, 1993; Akay et al., 2007).

The left and right portions of the right panel of Figure $8 \mathrm{~A}$ show mesothoracic protractor and retractor MNs during frontleg stepping without (left portion) and with (right protion) middle-leg CS stimulation. In the absence of CS stimulation, mesothoracic retractor motor neuron activity was in phase with front-leg stance and protractor activity with front-leg swing. When CS stimulation was applied during a protractor burst, it terminated protractor firing and activated the retractor motor neurons (second red line, right portion of right panel). When applied during a retractor burst (first and third red line, right portion of right panel), CS stimulation modestly increased retractor motor neuron firing and could increase retractor motor neuron burst duration (data not shown). The excitatory effect of CS stimulation on retractor motor neuron activity was quantified with a peristimulus analysis (Fig. $8 B$ ), which showed that in the bin from 50 to $100 \mathrm{~ms}$ after the stimulation began mean retractor MN spike rate increased from 60 to 210 spikes/s. The stair function at the top of the histogram shows that the distribution of front-leg stance beginning was approximately flat relative to when the CS stimulation was applied, and thus the increased mesothoracic retractor firing was not attributable to front-leg stance inadvertently primarily occurring simultaneous with CS stimulation.

When rhythmically applied at a frequency close to front-leg natural step-cycle frequency, CS stimulation could entrain protractor and retractor activity out of phase with front-leg stepping (Fig. 8C, compare right, left panels) (data from another experi- 
ment). Retractor MN bursts (gray bars) then coupled to CS stimulation and no longer to front-leg steps. Figure $8 D$ shows the phase of retractor burst beginning in front-leg step cycle (bottom panel) for front-leg steps without (black squares) and with (red squares) CS stimulation at a frequency of $0.7 \mathrm{~Hz}$ in yet another experiment. During front-leg steps without CS stimulation, retractor bursts reliably began at $\sim 250^{\circ}$ of front-leg step cycle. During CS stimulation, retractor MN bursts were coupled to the stimulation and occurred in all phases of the front-leg step cycle. Figure $8 D$, top panel, plots phase of retractor burst beginning versus stimulation cycle. Retractor motor neuron burst beginning coincided with the beginning of the stimulation ramp. Middle-leg sensory signals could thus overcome front-leg step sensory-induced entrainment.

\section{Discussion}

Locomotion requires coordination of locomotory appendages (legs, swimmerets) or body segments (leech, lamprey swimming). Very little is known in legged animals about the neural basis underlying this coordination. Previous work has shown that, in stick insect, central mechanisms play at most a minor role in interleg coordination. In particular, Ludwar et al. (2005) show that deafferented and selectively activated prothoracic CPGs do not drive the other segmental CPGs. We investigated here the role of movementinduced sensory feedback on the activity of walking CPGs in other body segments. Descending pathways activated by front-leg movement alone could entrain activated middle-leg and hind leg walking CPGs to fire in phase with front-leg movements, an activity pattern never seen in vivo. Experiments with intact front legs and middleleg stumps showed that this phase symmetry could be broken by middle-leg load signals and result in a wide variety of frontand middle-leg CPG phase relationships. These data suggest that interleg coordination in stick insect in vivo likely results from an interaction of interleg and intraleg sensory feedback pathways.

The role of central connections in limb and body segment coordination has been extensively investigated (for references, see Introduction). Stick insect legs are long relative to the insect's body size, and it could be argued that the importance of interleg influences shown here and the relative weakness of central coordinating influences in this species are attributable to this specialized anatomy. However, proprioceptor-derived interleg coordinating influences also play important roles in locomotion in a variety of other legged animals
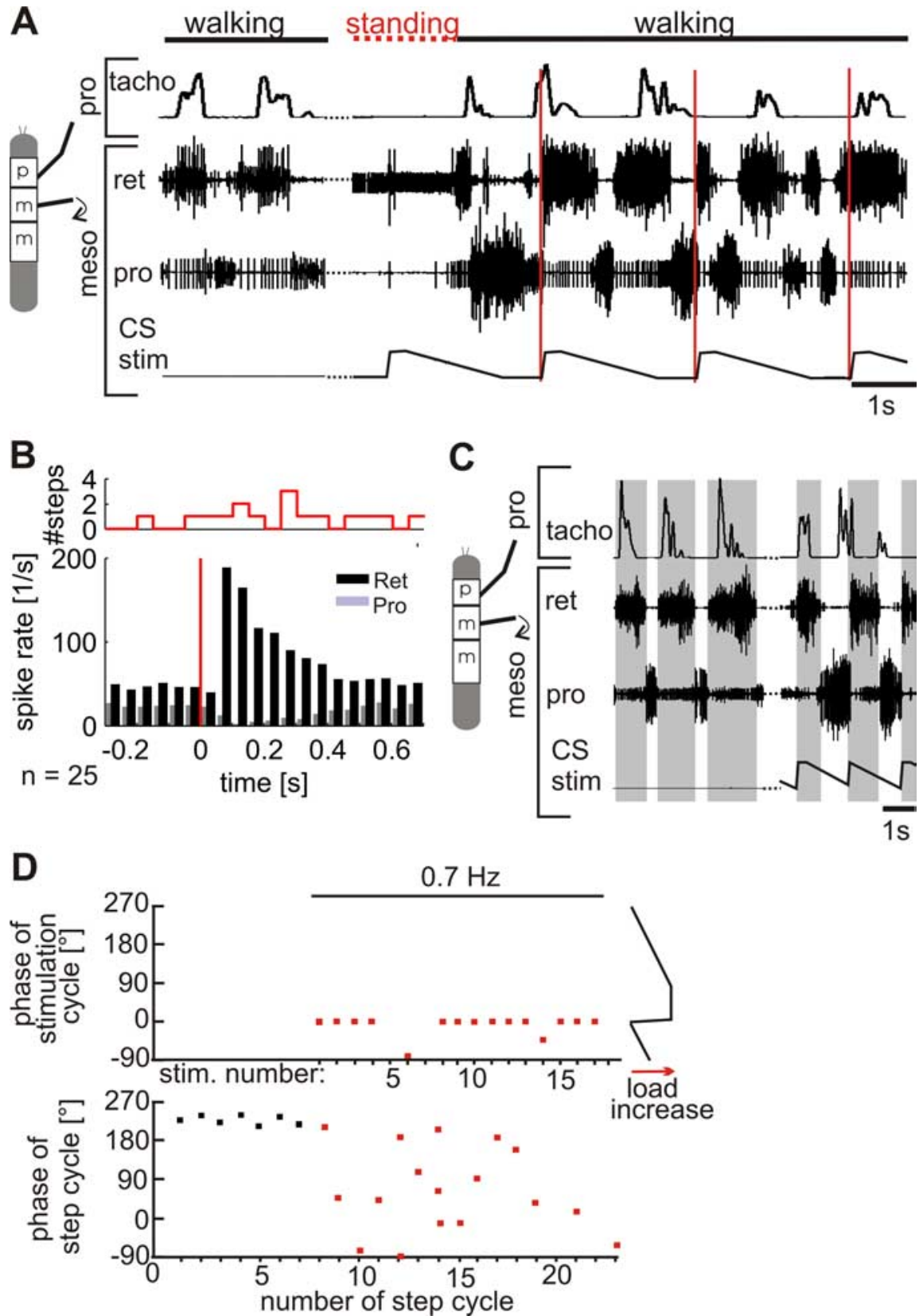

Figure 8. Local load signals could entrain mesothoracic TC joint CPG. $A$, Recordings of mesothoracic protractor and retractor MN activity during single front-leg stepping and simultaneous middle-leg $C S$ stimulation. Retractor MN activity increased with each CS stimulation. B, Stimulus time histogram: distribution of retractor MN activity from $0.3 \mathrm{~s}$ before to $0.7 \mathrm{~s}$ after middle-leg CS stimulation for stimulations during front-leg stepping. The red stair function at the top of the histogram shows the number of stance beginnings in each class. In the bin from 50 to $100 \mathrm{~ms}$, CS stimulation increased retractor MN activity from 60 to 210 spikes/s. C, Recordings (from another preparation) of mesothoracic protractor and retractor MN activity during single front-leg stepping (left panel) and during simultaneous middle-leg CS stimulation with a frequency of $0.7 \mathrm{~Hz}$ (right panel). Retractor MN bursts (gray bars) were entrained by $\mathrm{CS}$ stimulation and no longer coupled to front-leg steps. $\boldsymbol{D}$, Bottom, Phase of retractor burst beginning in front-leg step cycle plotted against front-leg step cycle number during only front leg steps (black squares) and during front-leg steps and simultaneous CS stimulation with a frequency of $0.7 \mathrm{~Hz}$ (red squares) in another preparation. During only front-leg steps, retractor motor neuron burst beginning reliably occurred at $\sim 250^{\circ}$ of front-leg step cycle. During $\mathrm{CS}$ stimulation, retractor MN bursts were coupled to the stimulation and occurred in all phases of front-leg step cycle. Top, Phase of retractor burst beginning in stimulation cycle plotted against stimulation cycle number. Retractor bursts coincided with stimulation beginnings (schemata on right shows (S stimulation). pro, Protractor; ret, retractor; tacho, tachometer trace.

(for references, see Introduction), and in some cases can overrule central connections (Johnston and Levine, 2002). The presence of central coordinating mechanisms should therefore not be taken as evidence that proprioceptive connections are not also present, nor that central connections are of primary importance 
behaviorally. The data reported here may thus have relevance for understanding interlimb coordination in a variety of organisms.

\section{Coupling of ipsilateral TC joint CPGs to front-leg stepping}

In leech, Manduca larvae, crayfish, lamprey, newt, and neonatal rat, a metachronal wave of motoneuron discharge propagates along the body with phase shifts of $1-25 \%$ between neighboring segments [leech, 20\% intact animal, $8 \%$ in vitro (Pearce and Friesen, 1984); Manduca, 8-10\% (Trimmer and Issberner, 2007); crayfish swimmerets, 25\% (Skinner and Mulloney, 1998); lamprey, 1\% (Wallén and Williams, 1984); newt swimming, 1.33.6\% (Delvolvé et al., 1997); data not analyzed with respect to intersegmental phase shifts in rat]. In swimmeret beating and forward swimming animals, this wave propagates from front to back (see above references), whereas in forward terrestrial locomotion it propagates from back to front [Manduca (Johnston and Levine, 1996b); centipede (Anderson et al., 1995); neonatal rat (Falgairolle and Cazalets, 2007)]. When the direction of the wave is taken into account, body segment-to-body segment phase shifts thus vary from -10 to $+25 \%$. During single front-leg stepping, stick insect ipsilateral mesothoracic and metathoracic retractor MN activity occurred approximately in phase with front-leg stance (retraction), and protractor MN activity with front-leg swing (protraction). Front-leg sensory feedback onto the caudal CPGs thus resulted in all three CPGs oscillating in phase, although there was a tendency for metathoracic retractor $\mathrm{MN}$ activity to begin shortly before mesothoracic retractor $\mathrm{MN}$ activity (Fig. 4C) (a negative phase shift similar to that seen in Manduca). Our data lie within the range observed in other systems, and close to their mean of $\sim 0 \%$.

With respect to the mechanisms maintaining intersegmental coordination, cycle-to-cycle coupling of intersegmental CPGs is seldom observed in deafferented stick insect ganglia (Bässler and Wegner, 1983; Büschges et al., 1995; Ludwar et al., 2005). Although these data show that central coupling pathways do exist in stick insect, the infrequency with which coupled activity is observed in deafferented preparations indicates that, unlike many systems mentioned previously, in deafferented preparations these pathways are generally either not active or are too weakly activated to coordinate the activity of CPGs in different segments.

These previous observations, when coupled with the data presented here showing that movement-induced interleg sensory interactions strongly entrain intersegmental CPG activity, suggest that the infrequent coupling observed in stick insect deafferented preparations could arise by at least two mechanisms. The first is dedicated central coordinating pathways lying parallel to the movement-induced coordinating pathways that presumably underlie the data presented here. The second is that the movement-induced pathways are the only coordinating pathways present in this system, and the infrequent coupling observed in deafferented preparations arises from CPG activity being sometimes able to activate the movement-induced pathways. It is important to note that this question has relevance not only to stick insect, and suggests that it is important to check whether, in systems with strong coupling of CPG activity in deafferented preparations, the central connections underlying this coordination are also activated by movement-induced sensory feedback (which is present in these systems when intact).

The strong dominance of front-leg movement-induced feedback is also interesting for at least two reasons. First, these legs are used to find new footholds as walking proceeds, and where they step strongly influences where the middle legs and hind legs step next (for review, see Cruse, 1990). The front-leg dominance shown here may thus reflect a behavioral need for front-leg sensory input and proprioceptive feedback to dominate interleg coordination. Second, in the systems noted above in which intersegmental CPG activity is strongly coupled in deafferented preparations, the relative importance of ascending versus descending central connections in maintaining this coordination remains unresolved (Cohen et al., 1992). If the suggestion made above that movement-induced and central coordinating pathways might have shared elements is true, stimulation of proprioceptive pathways may provide an additional methodology for examining this issue.

\section{Metathoracic TC joint CPG activation requires both front- and middle-leg presence}

In contrast to the mesothoracic TC joint CPG, stepping of a single front leg did not induce alternating activity in the metathoracic TC joint CPG (Fig. 3A), although connective recordings suggested that signals during front-leg stepping reach the metathoracic ganglion. These connectives contain $\sim 2000$ axons (Leslie, 1973), and we cannot as yet identify any of the neurons whose activity is changing. Previous work has shown that single middleleg stepping is also insufficient to activate the metathoracic TC joint CPG (Borgmann et al., 2007). However, in 11 of 12 experiments in which both the ipsilateral front and middle leg were present, alternating metathoracic protractor and retractor $\mathrm{MN}$ activity occurred. Activation of the metathoracic TC joint CPG thus requires intact ipsilateral front and middle legs. This activation did not require that the front and middle legs both be stepping, because alternating metathoracic activity continued to occur in $41 \%$ of two-leg stepping sequences in which only the front leg stepped and $36 \%$ in which only the middle leg stepped. That both legs were required for activation, although only one needed to be stepping, suggests that both rhythmic sensory input from the stepping leg and tonically activated sensory input from the unmoving leg are required for metathoracic TC joint CPG activation. An analogous situation may exist in lamprey, in which tonic activity in reticulospinal neurons can activate fictive swimming, and cutaneous sensory signals can induce long-lasting plateau potentials in reticulospinal neurons (Di Prisco et al., 1997) and thus both pathways contribute to the activation of segmental CPGs. The activating effects present when both legs are intact are long-lasting (Fig. 7), suggesting they may result from second messenger system activation or similar modulatory processes.

\section{Implications for interleg coordination in intact animals}

The state in which all three CPGs are active in phase does not correspond to any known gait, in all of which at least one ipsilateral leg is active out of phase with the others. The data in Figure 8 showing that middle-leg load signals can override front-leg derived sensory input likely provides a resolution for this apparent contradiction, in that local sensory feedback breaks the phase symmetry that front-leg input alone would induce. This interpretation is consistent with previous work on the effect of single middle-leg-derived sensory input on mesothoracic activity (Akay et al., 2004; Akay and Büschges, 2006; Ekeberg et al., 2004) and data from animals missing one middle leg except the coxa, in which the leg stump moves in phase with the front leg when unloaded, but shifts to moving in antiphase when a peg leg is provided (Wendler, 1964). Our results also provide a possible neural mechanism for tripod and tetrapod gait generation as follows: The stepping front leg would "specify" a phase to its ipsilateral caudal neighbors. As long as a leg is unloaded, it can follow front-leg swing more or less in phase, but load information would 
override the front-leg influence and thus allow one leg to be in stance when the other two are in swing (cf. Cruse, 1985). This neural mechanism also implies a simple solution for dealing with the loss of individual legs (cf. Schilling et al., 2007). The extent to which the data presented here may underlie the behavioral rules for interleg coordination (Cruse et al., 1995; Dürr et al., 2004) remains to be determined, and will require studying the combined intersegmental influences of movement, load, and position signals from leg proprioceptors.

\section{References}

Akay T, Büschges A (2006) Load signals assist the generation of movementdependent reflex reversal in the femur-tibia joint of stick insects. J Neurophysiol 96:3532-3537.

Akay T, Haehn S, Schmitz J, Büschges A (2004) Signals from load sensors underlie interjoint coordination during stepping movements of the stick insect leg. J Neurophysiol 92:42-51.

Akay T, McVea DA, Tachibana A, Pearson KG (2006) Coordination of fore and hind leg stepping in cats on a transversely-split treadmill. Exp Brain Res 175:211-222.

Akay T, Ludwar BCh, Göritz ML, Schmitz J, Büschges A (2007) Segment specificity of load signal processing depends on walking direction in the stick insect leg muscle control system. J Neurosci 27:3285-3294.

Anderson B, Shultz J, Jayne B (1995) Axial kinematics and muscle activity during terrestrial locomotion of the centipede Scolopendra heros. J Exp Biol 98:1185-1195.

Bässler U (1993) The walking and searching pattern of stick insects-a modular system composed of reflex chains and endogenuous oscillators. Biol Cybern 69:305-317.

Bässler U, Wegner U (1983) Motor output of the denervated thoracic nerve cord in the stick insect Carausius morosus. J Exp Biol 105:127-145.

Batschelet E (1981) Circular statistics in biology. New York: Academic.

Borgmann A, Scharstein H, Büschges A (2007) Intersegmental coordination: influence of a single walking leg on the neighboring segments in the stick insect walking system. J Neurophysiol 98:1685-1696.

Brunner von Wattenwyl K (1907) Die Insektenfamilie der Phasmiden. Vol. 2. Leipzig: Wilhelm Engelmann.

Büschges A (2005) Sensory control and organization of neural networks mediating coordination of multisegmental organs for locomotion. J Neurophysiol 93:1127-1135.

Büschges A, Schmitz J, Bässler U (1995) Rhythmic patterns in the thoracic nerve cord of the stick insect induced by pilocarpine. J Exp Biol 198:435-456.

Cang J, Friesen WO (2000) Sensory modification of leech swimming: rhythmic activity of ventral stretch receptors can change intersegmental phase relationships. J Neurosci 20:7822-7829.

Cang J, Friesen WO (2002) Model for intersegmental coordination of leech swimming: central and sensory mechanisms. J Neurophysiol 87:2760-2769.

Cattaert D, Le Ray D (2001) Adaptive motor control in crayfish. Prog Neurobiol 63:199-240.

Cheng J, Stein RB, Jovanović K, Yoshida K, Bennett DJ, Han Y (1998) Identification, localization and modulation of neural networks for walking in the mudpuppy (Necturus macalatus) spinal cord. J Neurosci 18:4295-4304.

Chrachri A, Clarac F (1987) Induction of rhythmic activity in motoneurons of crayfish thoracic ganglia by cholinergic agonists. Neurosci Lett 77:49-54.

Cohen AH, Ermentrout GB, Kiemel T, Kopell N, Sigvardt KA, Williams TL (1992) Modelling of intersegmental coordination in the lamprey central pattern generator for locomotion. Trends Neurosci 15:434-438.

Collins JJ, Stewart I (1993) Hexapodal gaits and coupled nonlinear oscillator models. Biol Cybern 68:287-298.

Cruse H (1985) Which parameters control the leg movement of a walking leg? The start of the swing phase. J Exp Biol 116:357-362.

Cruse H (1990) What mechanisms coordinate leg movement in walking arthropods? Trends Neurosci 13:15-21.

Cruse H, Müller U (1986) Two coupling mechanisms which determine the coordination of ipsilateral legs in the walking crayfish. J Exp Biol 121:349-369.

Cruse H, Bartling C, Cymbalyuk G, Dean J, Dreifert M (1995) A modular artificial neural net for controlling a six-legged walking system. Biol Cybern 72:421-430.

Delvolvé I, Bem T, Cabelguen JM (1997) Epaxial and limb muscle activity during swimming and terrestrial stepping in the adult newt, Pleurodeles waltl. J Neurophysiol 78:638-650.

Di Prisco GV, Pearlstein E, Robitaille R, Dubuc R (1997) Role of sensoryevoked NMDA plateau potentials in the initiation of locomotion. Science 278:1122-1125

Dürr V, Schmitz J, Cruse H (2004) Behavior-based modelling of hexapod locomotion: linking biology and technical application. Arthropod Struct Dev 33:237-250

Ekeberg O, Blümel M, Büschges A (2004) Dynamic simulation of insect walking. Arthropod Struct Dev 33:287-300.

Falgairolle M, Cazalets JR (2007) Metachronal coupling between spinal neuronal networks during locomotor activity in newborn rat. J Physiol 580:87-102.

Gabriel JP, Scharstein H, Schmidt J, Büschges A (2003) Control of flexor motoneuron activity during single leg walking of the stick insect on an electronically controlled treadwheel. J Neurobiol 56:237-251.

Graham D (1985) Pattern and control of walking in insects. In: Advances in insect physiology, Vol 18, pp 31-140. London: Academic.

Grillner S (2003) The motor infrastructure: from ion channels to neuronal networks. Nat Rev Neurosci 4:573-586.

Grillner S, Wallén P (2002) Cellular bases of a vertebrate locomotor systemsteering, intersegmental and segmental co-ordination and sensory control. Brain Res Brain Res Rev 40:92-106.

Haridas C, Zehr EP (2003) Coordinated interlimb compensatory responses to electrical stimulation of cutaneous nerves in the hand and foot during walking. J Neurophysiol 90:2850-2861.

Hill AA, Masino MA, Calabrese RL (2003) Intersegmental coordination of rhythmic motor patterns. J Neurophysiol 90:531-538.

Johnston RM, Levine RB (1996a) Locomotory behaviour in the hawkmoth Manduca sexta: kinematic and electromyographic analyses of the thoracic legs in larvae and adults. J Exp Biol 199:759-774.

Johnston RM, Levine RB (1996b) Crawling motor patterns induced by pilocarpine in isolated larval nerve cords of Manduca sexta. J Neurophysiol 76:3178-3195.

Johnston RM, Levine RB (2002) Thoracic leg motoneurons in the isolated CNS of adult Manduca produce patterned activity in response to pilocarpine, which is distinct from that produced in larvae. Invert Neurosci 4:175-192.

Kiehn O, Kjaerulff O (1998) Distribution of central pattern generators for rhythmic motor outputs in the spinal cord of limbed vertebrates. Ann N Y Acad Sci 860:110-129.

Lam T, Pearson KG (2002) The role of proprioceptive feedback in the regulation and adaptation of locomotor activity. Adv Exp Med Biol 508:343-355.

Leslie RA (1973) A comparison of the fine structure of thoracic and abdominal interganglionic connectives in the newly hatched and adult stick insect, Carausius morosus. Br Z Zellforsch Mikrosk Anat 145:299-309.

Liao JC (2007) A review of fish swimming mechanics and behaviour in altered flows. Philos Trans R Soc Lond B Biol Sci 362:1973-1993.

Ludwar BCh, Göritz ML, Schmidt J (2005) Intersegmental coordination of walking movements in stick insects. J Neurophysiol 93:1255-1265.

Marquardt F (1940) Beiträge zur Anatomie der Muskulatur und der peripheren Nerven von Carausius (Dixippus) morosus. Zool Jb Abt Ont Tiere 66:63-128.

Pearce RA, Friesen WO (1984) Intersegmental coordination of leech swimming: comparison of in situ and isolated nerve cord activity with body wall movement. Brain Res 299:363-366.

Pearson KG (2008) Role of sensory feedback in the control of stance duration in walking cats. Brain Res Rev 57:222-227.

Samara RF, Currie SN (2007) Crossed commissural pathways in the spinal hindlimb enlargement are not necessary for right left hindlimb alternation during turtle swimming. J Neurophysiol 98:2223-2231.

Schilling M, Cruse H, Arena P (2007) Hexapod walking: an expansion to Walknet dealing with leg amputations and force oscillations. Biol Cybern 96:323-340.

Schmitz J (1993) Load compensatory reactions in the proximal leg joints of stick insects during standing and walking. J Exp Biol 183:15-33.

Schmitz J, Delcomyn F, Büschges A (1991) Oil and hook electrodes for en passant recording from small nerves. In: Methods in neurosciences, Vol 4, 
Electrophysiology and microinjection (Conn P, ed), pp 266-278. San Diego: Academic.

Skinner FK, Mulloney B (1998) Intersegmental coordination of limb movements during locomotion: mathematical models predict circuits that drive swimmeret beating. J Neurosci 18:3831-3842.

Stein PS (2008) Motor pattern deletions and modular organization of turtle spinal cord. Brain Res Rev 57:118-124.

Trimmer B, Issberner J (2007) Kinematics of soft-bodied, legged locomotion in Manduca sexta larvae. Biol Bull 212:130-142.

Tunstall MJ, Roberts A (1990) NMDA applied to the spinal cord in Xenopus embryos reduces rostro-caudal delay during fictive swimming. J Physiol 425:92.

Tunstall MJ, Roberts A (1994) A longitudinal gradient of synaptic drive in the spinal cord of Xenopus embryos and its role in co-ordination of swimming. J Physiol 474:393-405.

Wallén P (1982) Spinal mechanisms controlling locomotion in dogfish and lamprey. Acta Physiol Scand Suppl 503:1-45.

Wallén P, Williams TL (1984) Fictive locomotion in the lamprey spinal cord in vitro compared with swimming in the intact and spinal animal. J Physiol 347:225-239.

Weidler DJ, Diecke FP (1969) The role of cations in conduction in the central nervous system of the herbivorous insect Carausius morosus. Z Vergl Physiologie 64:372-399.

Wendler G (1964) Laufen und Stehen der Stabheuschrecke Carausius morosus: Sinnesborstenfelder in den Beingelenken als Glieder von Regelkreisen. Z Vergl Physiologie 348:198-250. 